\title{
HISTORIA AMBIENTAL Y ECOCRÍTICA PARA ARQUITECTOS. EL POTENCIAL DE LAS HUMANIDADES AMBIENTALES PARA LA ARQUITECTURA Y EL URBANISMO
}

Tyana Santini 
Anales de Investigación en Arquitectura Vol.6, 2016. ISSN 2301-1505. Santini, T., 67-85

\section{TYANA SANTINI}

PhD y Maestría, Universidad de Kioto, Japón. Arquitecta, Universidad ORT Uruguay. Profesora asistente de la cátedra de Historia y Teoría de la Arquitectura. Universidad ORT Uruguay. 


\section{RESUMEN}

Las disciplinas hoy consideradas humanidades ambientales surgen de campos de estudio con larga trayectoria en el análisis de la relación del hombre con la naturaleza, y actualmente se proponen estimular una reflexión más cuidadosa de los postulados sobre el medio ambiente manejados en los medios y la academia.

Luego de una discusión sobre la crítica ambiental y la situación en la educación superior, este artículo explora el potencial de las intersecciones entre humanidades ambientales y arquitectura dentro de tres enfoques: material, crítico-teórico y político-administrativo. Los posibles aportes de las humanidades ambientales a la arquitectura y el urbanismo incluyen desde información sobre cambios concretos del paisaje hasta reflexiones sobre naturalezas imaginadas y sus efectos en la gestión del ambiente.

A través de esta discusión, este artículo espera contribuir al desarrollo de las reflexiones acerca de la relación entre el entorno construido y el natural mediante la integración de nuevas perspectivas sobre la naturaleza.

Palabras Clave: Humanidades ambientales, Historia ambiental, Ecocrítica, Ambiente construido, Arquitectura.

\section{ABSTRACT}

The environmental humanities have emerged from traditional academic disciplines with a long tradition in the study of the man-nature relationship, and share today the purpose of encouraging a more careful consideration of our assumptions regarding the environment and its problems.

After a brief discussion of the conflicting views of environmental issues in higher education, this article explores the potential intersections between environmental humanities and architecture in three areas: material, theoretical, and management. The inclusion of environmental perspectives from other fields can offer information on specific changes of a natural or urban landscape, analysis of imagined or symbolic natures, or critical views on the effects on our ideas of nature on environmental management.

Through this discussion, this article hopes to contribute to the integration of new perspectives on nature into the study of the relationship between the built environment and nature.

Keywords: Environmental humanities, Environmental history, Ecocriticism, Built environment, Architecture. 
Con la percepción que tenemos hoy del mundo a través de Google Earth, donde con pequeños movimientos podemos cambiar de escala con rapidez extraordinaria -zoom in: local, zoom out: global- es difícil imaginar el enorme impacto que tuvieron las primeras fotografías color de la tierra desde el espacio en nuestra percepción de la naturaleza. En los años 60, estas imágenes de un pequeño planeta suspendido en el vacío alteraron la percepción del medio ambiente e intensificaron la apreciación de la naturaleza como frágil (Heise, 2008). Comprender estos cambios en nuestra percepción del medio ambiente, su historia y sus consecuencias es uno de los intereses de las humanidades ambientales.

Muchas de las disciplinas hoy categorizadas como humanidades ambientales provienen de campos de estudio con larga trayectoria en el análisis de la relación hombre-naturaleza, como la antropología social, la geografía humana o la filosofía natural. Entre las disciplinas de mayor peso y crecimiento de esta nueva categoría se encuentran la Historia ambiental y la Ecocrítica, que a pesar de haber tenido orígenes independientes comparten hoy muchas perspectivas e intereses.

En arquitectura, el término historia ambiental se asocia generalmente al trabajo de Reyner Banham (1922-1988) y a su estudio del desarrollo de la tecnología del control del clima. ${ }^{1} \mathrm{Sin}$

1 Banham, R. (1969) Problemas de Historia Ambiental (editorial IIDEHA) embargo, la historia ambiental como disciplina se define como la historia del rol de la naturaleza en la vida humana (Stewart, 1988:352) o como la historia de las interacciones de las sociedades con el medio ambiente (White, 1985). Esta creciente rama interdisciplinar de la historia se suele dividir en tres grandes enfoques: el enfoque material, donde se estudian los cambios concretos del medio ambiente a través del tiempo y la relación con la historia de sus habitantes; el enfoque teórico-crítico, donde se analizan las diferentes maneras de entender y relacionarse con el medio ambiente, incluyendo la crítica a las actitudes contemporáneas; y el enfoque político-administrativo, donde se evalúan las decisiones que las sociedades han adoptado en relación a la gestión del ambiente a través de la historia (Stewart, 1998; McNeill \& Roe, 2013).

La ecocrítica, nacida de la crítica literaria, estudia la percepción y representaciones de la naturaleza en el arte, prensa, literatura, y mundos virtuales. Parte importante de sus objetivos es examinar la sustentabilidad como hecho cultural para entender de qué forma las representaciones de la naturaleza pueden afectar actitudes personales y prácticas sociales (Hochman, 2000). Los estudios hechos dentro de la ecocrítica se superponen con la historia ambiental especialmente en los enfoques teórico-crítico y político-administrativo. 


\section{CRISIS Y CRÍTICA AMBIENTAL}

En la educación superior, las distintas reacciones a los problemas ambientales han generado una situación particular. Predominan por un lado los llamados a la acción que denuncian la falta de compromiso con la sustentabilidad, mientras que por otro hay desconfianza ante el abuso de la retórica apocalíptica y la falta de perspectiva crítica sobre el tema (Peterson \& Wood, 2015). Las humanidades ambientales sirven actualmente de marco de discusión para estas dos posturas.

Los estudios realizados dentro de las humanidades ambientales no siempre están ligados a los problemas ambientales -especialmente los estudios históricos- sin embargo, estas disciplinas suelen presentarse como complemento de las ciencias, brindando un ámbito propicio donde realizar un análisis crítico de la situación. ${ }^{2}$

El (re)surgimiento de las humanidades ambientales estuvo impulsado en gran parte por la necesidad de generar una reflexión más cuidadosa acerca de los postulados sobre el medio ambiente que se manejan en los medios, la política y en la propia academia. Por este motivo,

2 Ver por ejemplo: http://environmental.humanities. ucla.edu/; https://ehp.stanford.edu/about

http://environment.harvard.edu/environmental-humanities-initiative-0; http://www.carsoncenter.uni-muenchen. de una de las tareas de las humanidades ambientales es extender el acervo de conocimientos y reflexiones sobre la relación hombre-naturaleza a otros públicos a través de la revisión y re-edición de las obras más influyentes en la comprensión actual del tema, como por ejemplo los escritos de los geógrafos Élisée Reclus (18301905) o Carl O. Sauer (1889-1975), la obra del historiador Lucien Febvre (1878-1976), o los tratados sobre las ideas de la naturaleza de Robert C. Collingwood (1889-1943) o Raymond H. Williams (1921-1988).

A pesar de que los objetivos finales de estas disciplinas suelen estar alineados con los objetivos de movimientos ambientalistas, algunas afirmaciones de historiadores ambientales y ecocríticos se encuentran en conflicto con los argumentos de estos movimientos. Por ejemplo, las naturalezas equivocadas a las que se pretende regresar (Cronon W. , 2013) y la idea de que alguna vez vivimos en armonía con la naturaleza son temas frecuentemente revisados debido a su repercusión. La visión pastoral de un pasado idealizado -con su expresión más armada en el primitivismo de Rousseau y manejada hoy por el anarco-primitivismo- tiene aparentemente más que ver con la literatura y mitos edénicos que con hechos reales (Stewart, 1998; Cronon, 2013; Casteel, 2016). Esta visión crítica no significa que el rol de los activistas ambientales en la creación de conocimiento sea despreciado (Jamison, 2003) y, al mismo tiempo, esta crítica es hecha en la mayoría de los casos por activos conservacionistas como William Cronon. 


\section{ENTORNO CONSTRUIDO Y NATURAL}

Los debates acerca de la importancia que debería tener la sustentabilidad en la educación superior no son ajenos al campo de arquitectura y urbanismo, donde la gran mayoría de los avances relacionados a los problemas ambientales se dan en las áreas técnicas, mientras que en la historia y teoría el tema es comparativamente poco tratado.

El medio natural es sin duda una parte ineludible del trabajo práctico y teórico de arquitectos y urbanistas, y ciertamente el estudio del paisaje y de la relación entorno construido con el natural han sido afrontados infinidad de veces desde Vitrubio en adelante. Sin embargo, a pesar de que actualmente resulte difícil independizar las reflexiones sobre el medio natural de las discusiones sobre los problemas ambientales, las distintas maneras en que son considerados estos temas generan una brecha en la reflexión que se le dedica a cada uno de ellos.

Hace una década Mark Jarzombek ${ }^{3}$ (2006) sostuvo que los debates en la arquitectura con respecto a la sustentabilidad se inclinan hacia las ciencias naturales a causa de la debilidad de los argumentos ambientalistas, cuyas premisas a veces suenan bien pero no dicen nada. En círculos académicos, los investigadores tienden a evitar el término sustentabilidad por su gene-

3 Mark Jarzombek es director del instituto de historia, teoría y crítica de arquitectura del Instituto de Tecnología de Massachusetts. ralidad y ambigüedad (Eastaway \& Støa, 2004), mientras que la arquitectura sustentable suele ser acusada de carecer de fundamentos teóricos (Tilder, 2007) y es entendido que la arquitectura en sí no va a ser mejor o peor por ser sustentable (Jarzombek, 2006). El abuso de lo ecológico como herramienta de marketing de construcciones de poco valor arquitectónico incrementa los prejuicios. Ante esta situación, existen algunos intentos de darle al tema mayor consistencia mediante la inclusión de obras de arquitectos reconocidos -como Peter Hall o Renzo Piano- o mediante la integración de discusiones sobre las diferentes actitudes frente a la naturaleza (Guy \& Moore, 2005; García de Diego \& Vázques Espí, 2007). El urbanismo y la sustentabilidad es el tema más ampliamente discutido -el trabajo de Roberto Fernández es un ejemplo en la región-, pero en relación a la trascendencia que tiene la problemática ambiental en el ámbito social y político, pocos académicos dedicados a la historia y teoría de la arquitectura se acercan al tema. Al igual que en otros campos, la reticencia a tratar el tema de la sustentabilidad no se debe a una negación de la importancia de los problemas ambientales, sino al rechazo de las respuestas dominantes ante este hecho y a la asociación del tema con sus facetas más ingenuas o evangelizadoras.

En los últimos tiempos se está viendo una inclusión de algunas teorías ambientales como la exploración de las raíces políticas de la noción de 
naturaleza de Bruno Latour ${ }^{4}$, sin embargo, una mayor inclusión de la extensa y diversa teoría ambiental desarrollada en las últimas décadas dentro de las humanidades permitiría ampliar considerablemente las posibilidades de análisis de la relación del ambiente construido con el natural. Por un lado permitiría incluir nuevos puntos de vista en la reflexión sobre las relaciones de la arquitectura y urbanismo con la naturaleza, y por otro, favorecería al desarrollo de la tan reclamada perspectiva crítica de las respuestas arquitectónicas a los problemas ambientales.

En las siguientes secciones se examinan las posibilidades que ofrecen las humanidades ambientales a las investigaciones en arquitectura y urbanismo, tomando como referencia los tres enfoques que se distinguen dentro de la historia ambiental: material, teórico-crítico, y político-administrativo. El objetivo no es revisar o re-categorizar los trabajos existentes sobre arquitectura y naturaleza, ${ }^{5}$ sino identificar posibles intersecciones disciplinares con las humanidades ambientales para ilustrar su potencial. Al igual que en la historia ambiental, los tres enfoques no preten-

4 Ver: Latour (2011) Why Do Architects Read Latour?, Perspecta 44

5 Algunas revisiones de escritos sobre la relación de la arquitectura con la naturaleza son: Menin y Samuel (2003) Nature and space: Aalto and Le Corbusier, Routledge; Luccarelli, M. (1995) Lewis Mumford and the Ecological Region: The Politics of Planning, Guilford Press; Iñaki Ábalos (2009) Naturaleza y Artificio: el ldeal Pintoresco en la Arquitectura y el Paisajismo Contemporáneos, Gustavo Gili; Bøe y Faber (2014) Raw: Architectural Engagements with Nature, Routledge. den tener límites estrictos sino servir de referencia a la organización del planteo.

Cada uno de los enfoques incluye reseñas y discusiones de temas basados en análisis de varias disciplinas, aunque las referencias a la historia ambiental y la ecocrítica son mayores debido a su importancia. En algunos casos, como en el enfoque material, se incluyen referencias a arquitectos que han incorporado trabajos recientes de las humanidades ambientales a sus estudios.

\section{ENFOQUE MATERIAL}

Aplicado al estudio de arquitectura y urbanismo, el enfoque material de las humanidades ambientales refiere aquí a la relación del entorno construido con características concretas del medio ambiente como el clima o los recursos naturales.

En este sentido uno de los desarrollos más importantes está ocurriendo en la historia ambiental urbana, donde se superpone el urbanismo en su aspecto material y social, con la historia natural y la historia de la tecnología. El estudio de las conexiones entre las ciudades y el medio ambiente implica afrontar temas tan variados como la verificación material de esta interacción, los acuerdos sociales asociados a estas conexiones o su dimensión política. A los estudios empíricos de infraestructura o gestión de la naturaleza de las ciudades se le suman reconsideraciones de teorías y revisiones de clásicos del pensamiento 
urbano como Mumford o Burgess y Park (Melosi 1993, Sachs 2016) que resultan en aportes valiosos para varias disciplinas.

Uno de los trabajos pioneros en la historia ambiental urbana es La Metrópolis de la Naturaleza (1991) de William Cronon donde se examina la relación del desarrollo económico de Chicago con la región rural del "gran oeste". Para Cronon, la evolución de Chicago no puede ser entendida sin tomar en cuenta la historia social de las interacciones entre las actividades urbanas y rurales, de la misma manera en que los cambios del paisaje de la región sólo pueden ser explicados por las actividades de la ciudad. A través del rastreo de la hibridación de sistemas naturales y humanos, Cronon pone de manifiesto la geografía del capital (Cronon W. , 2013, pág. 264) mostrando los movimientos de mercados e industrias -como la maderera o la agrícola- que fueron guiando el desarrollo de Chicago.

Numerosos relatos de la vida urbana permiten formar vividas imágenes de los acelerados cambios de una ciudad en crecimiento que representaba la antítesis geográfica de su duro entorno natural, una profecía de lo que Estados Unidos podría llegar a ser al escapar de su pasado rural (Cronon W. , 2013, págs. 9-14). Las reacciones generadas por estos cambios son detalladas por Cronon a través del libro, donde Louis Sullivan (1856-1924) es presentado como representante de quienes entienden a la naturaleza como vehículo de expresión del potencial del espíritu humano, en oposición a la visión de la obra humana como sacrilegio del entorno.

En el estudio de la historia de la relación entre la arquitectura y el medio natural también se están abriendo nuevos caminos gracias a la integración de perspectivas diferentes sobre el medio ambiente. El arquitecto inglés Dean Hawkes por ejemplo incluye varios análisis de historia ambiental, estudios culturales y crítica literaria que enriquecen sus últimos trabajos con datos precisos sobre la historia del clima, percepciones de la naturaleza y consideraciones sobre los cambios en las presunciones del efecto del clima en la cultura.

De la misma manera en que Reyner Banham integró la historia de la tecnología al análisis histórico de la arquitectura, Hawkes integra la historia del clima con el fin de examinar la evolución de su relación con la arquitectura británica. Si bien los cambios climáticos son mucho menos dramáticos que los tecnológicos, Hawkes considera las alteraciones desde la pequeña edad de hielo - período de inviernos gélidos ocurrido en el hemisferio norte entre los siglos 14 y 19- hasta los aumentos de temperatura ocurridos por la urbanización en el siglo 20 (Hawkes, 2008). La arquitectura es examinada no sólo como una respuesta instrumental al clima sino como una respuesta cultural, por lo que la selección de casos de estudio no está basada simplemente en la eficiencia. Hawkes sostiene que las diferentes actitudes hacia el clima están plasmadas en la arquitectura, como 
en la casa de fin de semana de Alison y Peter Smithson -Upper Lawn (1959-62)- donde se rechazan deliberadamente las posibilidades de confort de la época, buscando que la vivienda interactúe con el clima en vez de servir como barrera protectora.

\section{ENFOQUE TEÓRICO CRÍTICO}

La mayor contribución que las humanidades ambientales pueden ofrecer es la de examinar las ideas sobre la naturaleza, estudiar la relación de estas ideas con nuestras interacciones con el medio ambiente y explorar los significados que asociamos a estas interacciones.

Dentro del campo de la arquitectura el ejemplo más conocido de este tipo de reflexión es quizás el contraste entre jardines ingleses y franceses. En Nuestras Ideas sobre lo Sublime y lo Bello (1904-14[1757]) Edmund Burke asigna la regularidad geométrica de los jardines a la 'desafortunada' tendencia humana de hacer de sí misma y su obra la medida de la excelencia de todas las cosas. Al menos en los jardines, observa Burke, la naturaleza pudo escapar de la disciplina humana por haber comprendido que las ideas matemáticas no son la verdadera medida de la belleza. Si bien la nacionalidad de los jardines está sólo implícita en las observaciones de Burke, a fines del siglo 18 esta idea se difunde y se convierte en la afirmación de que el estilo natural de los jardines ingleses expresa la libertad que en este país se disfruta, mientras que el orden racional impuesto en los jardines franceses representa el despotismo político bajo el que vivieron sus creadores (Duckworth, 2005).

En parques y jardines de Francia, la tendencia hacia el control de la naturaleza es aún hoy más notoria que en otros países europeos, pero se asocia ya no al despotismo sino a la herencia racionalista. Una comparación de la administración de parques berlineses y parisinos (Skandrani \& Prévot, 2015) muestra que mientras en Berlín se promueve la participación de los usuarios y se permite la vegetación espontanea entendida como un oasis silvestre, en París la naturaleza es embellecida para ser observada y la vegetación no regulada es considerada como un descuido. En Alemania, el romanticismo estimuló la adopción de un estilo más silvestre (Skandrani \& Prévot, 2015:147) que al estar hoy alineado con las estéticas de la naturaleza manejadas por movimientos ambientalistas (Carlson, 2010) no se asocia con descuido sino con una naturalidad positiva.

La idea de que la relación con el medio ambiente puede variar según la cultura no fue siempre considerada ni compartida en todos los círculos académicos. A principios del siglo 20 se dio un cambio de ideologías con respecto a la influencia del entorno natural en la cultura que causó un gran impacto en las disciplinas de historia, geografía y antropología pero no tanto en arquitectura. El supuesto de que una cultura puede ser explicada por el medio ambiente en el que se desarrolló -idea conocida como determinis- 
mo ambiental- dio paso a la idea que sostenía que, si bien la naturaleza impone ciertos límites al desarrollo, las características culturales no siempre encuentran razón en el entorno natural y deben ser explicadas por factores históricos y sociales -idea conocida como posibilismo.

El distinto grado de influencia que tuvo este cambio ideológico en diferentes disciplinas se hace evidente en los estudios de arquitectura rural japonesa realizados durante la década de 1930 por el geógrafo R. B. Hall y el arquitecto Bruno Taut.

Dentro de la geografía, las afirmaciones que pudieran relacionarse con el determinismo eran evitadas, ya que se entendía que esta ideología estaba asociada a argumentos colonialistas sobre la superioridad de algunas culturas sobre otras. Basar la explicación de una cultura y sus expresiones materiales -como la arquitecturaexclusivamente en datos geográficos hubiera sugerido que hay sólo una respuesta posible a la adaptación a un determinado clima, y en consecuencia, que el desarrollo cultural está determinado por las condiciones del medio ambiente. Por esta razón, a pesar de que en los estudios de Hall muchas características de las construcciones se explican cómo respuestas al clima, el desarrollo regional y la influencia cultural de países vecinos adquieren mayor importancia.

Los debates sobre la influencia de la naturaleza no tuvieron la misma importancia dentro del campo de la arquitectura, donde las ideas deterministas no tenían una asociación tan negativa. ${ }^{6}$ De hecho, para Taut, el hecho de que diferentes culturas se adapten de la misma forma a entornos naturales similares era una prueba incuestionable de que todos los hombres eran igualmente lógicos. En consecuencia, Taut busca la verificación de esta idea en la arquitectura haciendo énfasis en la similitud de distintos tipos de viviendas europeas y japonesas que fundamenta en la adaptación a las condiciones naturales (Santini \& Taji, 2015).

Las interpretaciones de nuestra interacción con la naturaleza implican generalmente la discusión de temas mucho más complejos que la gestión del entorno natural, como los sistemas políticos o los supuestos acerca del desarrollo cultural. La actividad humana está inevitablemente atada a la naturaleza, y las maneras de entender esta relación afecta tanto a las concepciones de la historia como a la manera en que el futuro es imaginado y planeado.

En la literatura utópica, el problema de la satisfacción de las necesidades humanas se resuelve ya sea imaginando una abundancia generalizada basada en una expansión tecnológica - utopías de la abundancia - o presentando a las necesidades humanas como reconfiguradas

6 Por otras diferencias de interpretación entre disciplinas ver Vellinga, M. (2011) The End of the Vernacular: Anthropology and the Architecture of the Other, Architecture, 23(1), 171-192. Vellinga (2011:183) nota que la crisis de representación tan influyente en el campo de la antropología, geografía, y estudios culturales no parece haber tenido ningún efecto dentro del campo de la arquitectura. 
o reducidas -utopias sustentables (Garforth, 2005). El planteo de las utopías sustentables presenta un hedonismo alternativo anti-consumista (Soper, 2008) en el que los habitantes buscan mejorar su calidad de vida por medios alternativos a los de la sociedad de consumo.

Una de las obras utópicas sustentables más influyentes en los movimientos ambientalistas es la novela Ecotopía (1975) (fig.1) de Ernest Callenbach (1929-2012). ${ }^{7}$ En la novela, el país Ecotopía es una sección emancipada de los Estados Unidos con su capital en San Francisco, donde gracias a la intervención del gobierno se logró un entorno donde lo urbano y lo natural se mezclan en una ciudad de alta densidad, usos mixtos, y con predominio de transporte público. En Ecotopía la naturaleza es protagonista incluso en el centro de la ciudad donde es usada con fines recreativos y de producción de alimentos. El cultivo, la caza y la pesca son actividades urbanas llevadas a cabo diariamente por sus ciudadanos, quienes gozan de un saludable estilo de vida facilitado por el entorno.

Según el análisis de Drennig8 (2010), las ideas de Callenbach han tenido una gran influencia en la visión de ciudades alternativas en Norteamérica, y esto se manifiesta no tanto en las ciudades reales sino en sus representaciones. Analizando el caso del eje Portland-Seattle-Van-

\footnotetext{
7 Eco del griego oikos: hogar y topia: lugar.

8 George Drennig, investigador de la producción cultural del espacio, University of Duisburg-Essen's ARUS, Alemania.
}

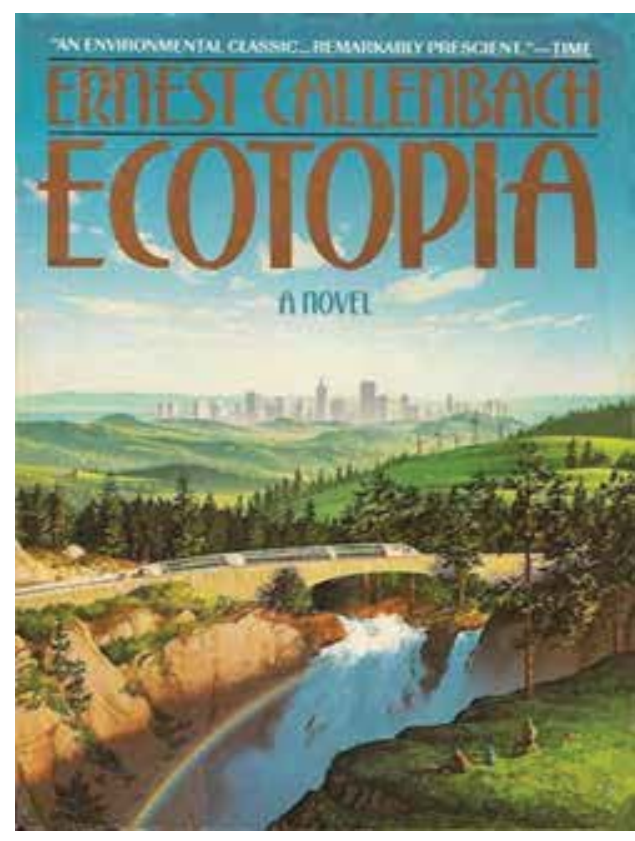

Figura 01.

Portada de Ecotopía (1975), de Ernest Callebach. Utopía sustentable de gran influencia en la visión de ciudades alternativas en Norteamérica.

IMAGEN: goodreads. 
couver, Drennig observa que las imágenes de estas ciudades creadas por los medios comparten muchas características con Ecotopía -especialmente el énfasis de la vida al aire libre. Las visiones de futuros sustentables como Ecotopía son en ocasiones objetadas por estar basadas en sistemas sociales y políticos que tienden a regímenes totalitarios (Peterson \& Wood, 2015; Mathisen, 2001). Para mantener el orden y el equilibro entre el medio natural y los humanos - pocas veces considerados como parte de la naturaleza- el estilo de vida de los ciudadanos de Ecotopía conlleva el dilema de felicidad versus libertad, típico de la ficción utópica (Tschachler, 1984:305). La desconfianza que genera la visión de Callenbach se relaciona a su insinuación de que la solución a los problemas ambientales no se logra mediante regulaciones sino mediante el adoctrinamiento. De todas formas, el mundo ilustrado en Ecotopía presentó un modelo que desafía los límites tradicionales entre la ciudad y la naturaleza del modelo urbano norteamericano (Drennig, 2010) que sigue sirviendo de referencia.

\section{ENFOQUE POLÍTICO ADMINISTRATIVO}

Nuestra relación con la naturaleza está actualmente mediada por instituciones públicas y privadas que la regulan, protegen, explotan o administran. En distintos momentos históricos la naturaleza fue concebida como objeto espiritual, científico o religioso, y emerge a mediados del siglo 20 como un objeto político-cultural protagonista en los medios y debates sobre acuer- dos internacionales (Hochman, 2000). Los debates sobre el medio ambiente se confunden con discusiones sobre desarrollo, especialmente en Latinoamérica donde la naturaleza es entendida como un recurso (Gudynas, 1999), Io que convierte al examen de su gestión en un tema de creciente importancia. ${ }^{9}$

Siguiendo las líneas de William Cronon, la historiadora brasileña Lise Sedrez ${ }^{10}$ analizó la Bahía de Guanabara en Río de Janeiro enfocándose en el desarrollo de las instituciones que la administraron. En la gestión de la Bahía intervino un complejo grupo de organizaciones públicas y privadas. Sin embargo Sedrez remarca el hecho de que el principal administrador de los recursos naturales fue siempre el estado, incluso cuando no fue consciente de ello. La relación de la ciudad con la bahía cambió drásticamente durante las políticas de desarrollo, especialmente con las reformas urbanas de Pereira Passos a comienzos del siglo 20. El énfasis en el embellecimiento del plan no sólo causó el conocido desplazamiento de la población que estimuló el crecimiento de las favelas, sino que generó un impacto ambiental que incluyó desde la contaminación de las aguas de la bahía por las obras de saneamiento, hasta el cambio de fauna que se dio con la importación de gorriones hecha para que Río tuviera los mismos pájaros que

9 Eduardo Gudynas, investigador de Naturaleza en América Latina, CLAES

10 Lise Sedrez es también fundadora y editora de Online Bibliography on Environmental History of Latin America: http://web.csulb.edu/projects/laeh/index.html 
Europa (Sedrez, 2004:92). Si bien puede plantearse que al hacerse estos cambios no se era plenamente consciente de sus consecuencias a largo plazo, el conocimiento de los efectos de la urbanización no representa tampoco una garantía de una adecuada gestión, principalmente porque no hay acuerdo en lo que es adecuado. La administración de Guanabara es hoy llevada a cabo por organizaciones integradas por ingenieros, científicos, burócratas, y militares -a los que ahora se suman ciudadanos y ambientalistas- quienes persiguen objetivos a veces contradictorios y esto deriva en prácticas inconexas y discontinuas.

El enfoque hacia la gestión del ambiente está en permanente cambio y hoy incluye ideas de desarrollo sostenible, conservación y justicia social que aumentan su complejidad. Las intenciones de quienes se inclinan hacia la justicia social pueden ser contradictorias con las de quienes se inclinan hacia la conservación. Algunos elementos del imaginario ambientalista por ejemplo se encuentran en conflicto con las actividades de las clases más comprometidas -como las industrias de extracción o tipos de producción agrícola considerados ahora perjudiciales- lo que causa nuevos debates (Sills, 1975; Drenning, 2010).

La antropóloga social Kay Milton (1991) sostiene que los desacuerdos sobre los problemas ambientales tienen su base en profundas diferencias de valores y distintas presunciones acerca de cómo funciona el mundo. Por otra parte,

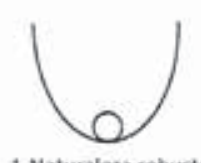

1-Naturaleza robusta

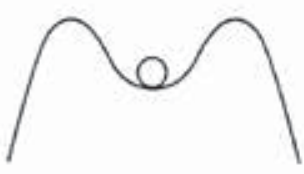

3-Naturaleza robusta dentro de ciertos limites

Figura 02.

Cuatro mitos de la naturaleza.

Visiones de la resistencia de la naturaleza frente a la explotación.

IMAGEN: Milton, K. (1991).

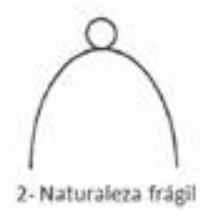

4- Naturaleza caprichosa
. 
dentro de una misma organización suelen coexisten generalmente diferentes actitudes frente a la naturaleza que pueden generar oposiciones o sesgar las decisiones políticas. Como parte del análisis de los debates sobre políticas ambientales británicas, Milton utiliza los Ilamados cuatro mitos de la naturaleza ${ }^{11}$ que sintetizan diferentes enfoques asociados a supuestos sobre la resistencia del medio ambiente (fig.2): naturaleza robusta, vista de este modo por grupos que promueven la explotación; naturaleza frágil, perspectiva de los proteccionistas que entienden que una vez que se pierde el equilibro éste es difícil de recobrar; naturaleza robusta dentro de ciertos límites, perspectiva según la cual la naturaleza se puede explotar dentro de ciertos límites establecidos por conocimientos científicos; y naturaleza caprichosa, visión que sostiene que la previsión y planeamiento son imposibles porque no se puede saber cómo va a evolucionar (Milton, 1991). La realidad es lógicamente más compleja y distintas visiones pueden ser mantenidas simultáneamente para diferentes actividades. Sin embargo estos estereotipos esquemáticos sirven como herramienta para aproximarse a la comprensión de la forma en que las ideas sobre la naturaleza se suman a la compleja trama de intereses económicos y políticos que intervienen en la administración del ambiente.

Uno de los debates relacionados a la gestión del medio ambiente que afecta directamente a la arquitectura es el desarrollo de indicadores y

11 Adaptados a la teoría cultural por Thompson (1986). certificaciones, actualmente en proceso de internacionalización. La certificación más extendida, y en consecuencia la más cuestionada, es la americana LEED ${ }^{12}$. Sus críticos sostienen que acaparó los mercados no por sus ventajas sino por sus estrategias de marketing, mientras que también existe desconfianza en cuanto a la real eficacia energética de los edificios certificados (Guy \& Moore, 2005:69; Scofield, 2009; Newsham, Mancini, \& Birt, 2009). LEED hoy compite con su contraparte británica, BREEAM ${ }^{13}$ y la más reciente certificación alemana $\mathrm{DGNB}^{14}$. Ésta última es la más aclamada en el mundo occidental $^{15}$, en parte por haber podido aprender de los errores de las pioneras LEED y BREEAM, logrando una certificación más flexible que evalúa el ciclo completo del edificio (Eberl, 2010). A pesar de las críticas estos certificados han ayudado a popularizar la consideración de la eficiencia energética, al menos en construcciones de gran porte. Al mismo tiempo, la preocupación por la homogeneización que pudiera causar la adopción de estándares internacionales en contextos diferentes ha llevado a que las discusiones ya no se limiten a aspectos técnicos sino que las consideraciones se extienden a la especificidad cultural de las adaptaciones al medio, la adaptación de estos estándares a construcciones tradicionales, y el estudio de nociones

12 Leadership in Energy and Environmental Design.

13 Building Research Establishment Environmental Assessment Method.

14 Deutsche Gesellschaft für Nachhaltiges Bauen.

15 En Asia lidera la certificación Japonesa CASBEE. 
culturales de la naturaleza implícitas en los distintos certificados (Cole \& Valdebenito, 2013; Blaviesciunaite \& Cole, 2011; Dirlich, 2012).

\section{CONSIDERACIONES FINALES}

Luego de este breve examen del potencial de las humanidades ambientales para las reflexiones arquitectónicas y urbanísticas, es necesario señalar también su principal limitación.

A diferencia de teorías abarcativas aplicables a varios contextos contemporáneos -como las del antropólogo Marc Auge o los sociólogos Saskia Sassen y Manuel Castells-, las investigaciones de ecocríticos y otros investigadores de las humanidades ambientales tienden a ser todavía muy específicas y difíciles de transponer a situaciones generales. No existe, al menos por el momento, una gran teoría de la naturaleza que podamos consultar o una conceptualización sobre los ciudadanos globales y el medio ambiente que pueda aplicarse a distintos medios culturales.

De todas formas, los estudios de estas disciplinas pueden brindar datos concretos sobre cambios de un paisaje natural o urbano -como los trabajos de Sedrez o Cronon- así como también reflexiones sobre naturalezas imaginadas y simbólicas, sobre nuestras interacciones con el medio ambiente, y sobre las visiones del futuro.

Las humanidades ambientales contribuyen también sin duda al desarrollo de una visión crí- tica sobre las respuestas de los creadores del entorno construido a los problemas ambientales. Aún si se considera que la eficiencia energética no tiene efecto sobre la calidad arquitectónica de un edificio, la sustentabilidad como hecho cultural y herramienta política permiten y merecen un mejor análisis. Los debates sobre sustentabilidad Ilevan implícitas ideologías y presunciones sobre tipos de desarrollo, de ciudades, de edificios y de estilos de vida que deben ser examinados.

Por último, vale la pena notar que a pesar de que los arquitectos incluyen regularmente referencias a trabajos de otras disciplinas, lo contrario es mucho menos frecuente. El conocimiento que los arquitectos tienen de los procesos involucrados en la creación del ambiente construido -ya sean procesos materiales, sociales o ideológicos- puede resultar de gran valor a las discusiones de las humanidades ambientales.

RECIBIDO: 10 de octubre 2016 ACEPTADO: $1^{\circ}$ de diciembre 2016 


\section{BIBLIOGRAFÍA}

Abalos, I. (2009). Naturaleza y artificio: el ideal pintoresco en la arquitectura y el paisajismo contemporáneos. Barcelona: Gustavo Gili.

Blaviesciunaite, A., \& Cole, R. J. (2011). The cultural values embedded in building environmental assessment methods: a comparison of LEED and CASBEE. Proceedings of the International Sustainable Building Conference. Kansas City, Missouri, mar. 23-25.

Bøe, S., \& Faber, H. (2014). Raw: Architectural Engagements with Nature. London: Routledge.

Burke, E. (1904-14). A philosophical inquiry into the origin of our ideas of the sublime and beautiful. New York: P.F. Collier \& Son Company.

Callenbach, E. (1975). Ecotopia: The notebooks and reports of William Watson. New York: Bantam.

Carlson, A. (2010). Contemporary environmental aesthetics and the requirements of environmentalism. Environmental Values, 19(3), 289-314.

Casteel, S. (2016). Pastoral. En J. Adamson., W. A. Gleason, \& D. N. Pellow (Eds.). Keywords for environmental studies. (pp. 158-161). Nueva York: NYU Press.

Cole, R. J., \& Valdebenito, M. J. (2013). The importation of building environmental certification systems: international usages of BREEAM and LEED. Building Research and Information, 41(6), 662-676.
Cronon, W. (1991). Nature's Metropolis: Chicago and the Great West. London: W. W. Norton $\&$ Company.

Cronon, W. (2013). The trouble with wilderness: or, getting back to the wrong nature. En U. R. McNeill. Global environmental history. An introductory reader. (pp. 339-363). London: Routledge.

Dirlich, S. (2012). The building stock and traditional building principles: sustainability assessment for historic buildings. (pp. 31-38). Proceedings of the 1st International Conference on Building Sustainability Assessment. Porto, Portugal, may 23-25.

Drennig, G. (2010). Cities of desire: ecotopia and the mainstreet cascadia imaginary. REAL. Yearbook of Research in English and American Literature. (26), 145-158.

Duckworth, A. M. (2005). Landscape. En J. Todd. Jane Austen in context. Cambridge: Cambridge University Press.

Eastaway, M., \& Støa, E. (2004). Editorial: Dimensions of housing and urban sustainability. Journal of Housing and the Built Environment, 19(1), pp.1-5.

Eberl, S. (2010). DGNB vs. LEED: a comparative analysis. Central Europe towards Sustainable Building Conference (CESB). (pp. 543546). Prague, june 30-july 2.

García de Diego, M., \& Vázques Espí, M. (2007). Prestigio, arquitectura y sostenibilidad. Revista Arquitectos, 182(3), 58-61. 
Garforth, L. (2005). Green Utopias: Beyond Apocalypse, Progress and Pastoral. Utopian Studies, 16(3), 393-427.

Glacken, C. (1992). Reflections on the history of western attitudes to nature. GeoJournal, 26(2), 103-111.

Gudynas, E. (1999). Concepciones de la naturaleza y desarrollo en América Latina. Persona y Sociedad, 13(1), 101-125.

Guy, S., \& Moore, S. A. (2005). Sustainable architectures: critical explorations of green building practice in Europe and North America. Nueva York: Spon Press.

Guy, S., \& Moore, S. (2007). Sustainable architecture and the pluralist imagination. Journal of Architectural Education (1984). 60(4), 1523.

Hawkes, D. (2008). The architecture of climate: studies in environmental history, Smythson and the Smithsons. 25th Conference on Passive and Low Energy Architecture. (paper 151). Dublin, oct., 22-24.

Hawkes, D. (2012). Architecture and climate: an environmental history of British architecture, 1600-2000. London: Routledge.

Heise, U. (2008). Sense of place and sense of planet: the environmental imagination of the global. Nueva York: Oxford University Press.

Hochman, J. (2000). Green cultural studies. En L. Coupe. The green studies reader. (pp. 187192). Nueva York: Routledge.
Jamison, A. (2003). The making of green knowledge. The contribution from activism. Futures, 35, 703-716.

Jarzombek, M. (2006). Sustainability: fuzzy systems and wicked problems. Log, (8), 7-12.

Latour, B. (2011). Why Do Architects Read Latour? Perspecta, 44, 64-69.

Lucarelli, L. (1997). Lewis Mumford and the ecological region: the politics of planning. London: The Guilford Press.

Mathisen, W. (2001). The Underestimation of Politics in Green Utopias: The Description of Politics in Huxley's Island, Le Guin's The Dispossessed, and Callenbach's Ecotopia. Utopian Studies, 12(1), 56-78.

McNeill, J. R., \& Roe, A. (2013). Global environmental history. An introductory reader. London: Routledge.

Melosi, M. V. (1993). The place of the city in environmental history. Environmental History Review 17(1), 1-23.

Menin, S., \& Samuel, F. (2003). Nature and Space: Aalto and Le Corbusier. London: Routledge.

Milton, K. (1991). Interpreting environmental policy: a social scientific approach. Journal of Law and Society, 18(1), 4-17.

Morton, T. (2009). Ecology without nature: rethinking environmental aesthetics. Cambridge, MA: Harvard University Press. 
Newsham, G. R., Mancini, S., \& Birt, B. J. (2009). Do LEED-certified buildings save energy? Yes, but... Energy \& Buildings, 41, 897-905.

Peterson, R., \& Wood, P. W. (2015). Sustainability. Higher education new fundamentalism. Nueva York: National Association of Scholars.

Sachs, A. (2016). Lewis Mumford's Urbanism and the Problem of Environmental Modernity. Environmental History, 21, 638-659.

Santini, T., \& Taji, T. (2015). Robert B. Hall's Studies on Japanese Rural Architecture, through a comparison with Bruno Taut's writings. Journal of Architecture and Planning (Transactions of AIJ), 80, 1661-1670.

Scofield, J. H. (2009). Do LEED-certified buildings save energy? Not really. Energy \& Buildings, 41, pp. 1386-1390.

Sedrez, L. F. (2004) The bay of all beauties: State and environment in Guanabara Bay, Rio de Janeiro, Brazil, 1875-1975. (Tesis doctoral). Recuperado el 17 de Septiembre de 2016, desde http://www.sedrez.com/ docs/Sedrezdiss1.pdf

Sills, D. (1975). The Environmental Movement and Its Critics, en Human Ecology, 3(1), 1-41.

Skandrani, Z., \& Prévot, A. C. (2015). Beyond green-planning political orientations: Contrasted public policies and their relevance to nature perceptions in two European capitals. Environmental Science \& Policy. 52, 140 -149 .
Soper, K. (2008). Alternative hedonism, cultural theory and the role of aesthetic revisioning. Cultural Studies, 22(5), 567-587.

Stewart, M. A. (1998). Environmental history: profile of a developing field. The History Teacher, 31(3), 351-368.

Tilder, L. (2007). Review of "Ten Shades of Green: Architecture and the Natural World" Buchanan, P. and Frampton, K. (eds.). Journal of Architectural Education, 60(4), 60-61.

Tschachler, H. (1984). Despotic Reason in Arcadia? Ernest Callenbach's Ecological Utopias. Science Fiction Studies, 11(3), 304-317.

Vellinga, M. (2011). The End of the Vernacular: Anthropology and the Architecture of the Other. Architecture, 23(1), 171-192. 